\title{
Comparison of membrane phospholipid and its fatty acid compositions of the salivary glands from male and female rats
}

\author{
Yasunaga Kameyama, Koji Yashiro, Masamichi Ohno, Ryoichi Funabiki, \\ Takehisa Takenaka* and Yutaka Yokota \\ Department of Oral Biochemistry (Chief: Prof. Yutaka Yokota), \\ *Department of Endodontics (Chief: Prof. Yoshiyuki Mukoyama), \\ Gifu College of Dentistry, 1851-1 Hozumi, Motosu-gun, Gifu 501-02, Japan
}

[Accepted for publication: December 20, 1984]

Key words: membrane phospholipid / fatty acid / sexual difference / rat salivary glands

\section{Introduction}

It has been clarified that cyclic nucleotides and calcium ions have a critical role in cellular control mechanisms for the secretory process as second messengers ${ }^{1)}$. Furthermore, it has become clear that membrane phospholipids participate in the first reaction of secretory mechanisms ${ }^{2}$. In addition, phospholipids are thought of as a pool of arachidonic acid and that metabolites have many functional action on mammalian cells $^{3,4)}$. In these respects, salivary glands are useful model system for the studies of receptor mediated secretory mechanism ${ }^{1)}$. However, there is less information available about the basis analysis of membrane phospholipid composition by considering the difference of each of the three major salivary glands. Therefore, using rat parotid, submandibular and sublingual glands, we analyzed the composition of their phospholipids and fatty acyl chains, and observed that the sublingual gland was slightly different from the other two glands.

\section{Materials and Methods}

Ten male and female Sprague-Dawly rats, 9 weeks of age, were used and maintained under similar diet (Oriental MF solid rat chow, Oriental Kobokogyo, Tokyo). After fasting overnight, the rats were sacrificed by bleeding under light ether anesthesia and then the salivary glands (parotid, submandibular, sublingual) were removed with care to avoid mingling with adipose and connective tissues. Each salivary gland was cut into small pieces and homogenized in 2-3 times volume of ice-cold $0.9 \% \mathrm{NaCl}$ solution by a Potter-Elvehjem homogenizer.

Total lipids of salivary glands were extracted directly from obtained homogenate by the method of Bligh and Dyer ${ }^{5)}$. The first chloroform solution in the procedure of lipid extraction contained $50 \mu \mathrm{g} / \mathrm{ml}$ of BHT (2,6-di-tert-butyl-p-cresol) to avoid the oxidation of unsaturated fatty acids. The resulting lipids were stored in $\mathrm{CHCl}_{3}$ / $\mathrm{CH}_{3} \mathrm{OH}(6: 1, \mathrm{v} / \mathrm{v})$ under nitrogen at $-60^{\circ} \mathrm{C}$. Phospholipids were separated from neutral lipids on a silica gel thin-layer chromatography (TLC) plate (Merck). Lipid phosphorus was determined by the procedure of Bartlett $^{6)}$, as modified by Marinetti $^{\top}$. In order to separate minor phospholipids completely, total phospholipids were applied to the analysis of two dimensional chromatography on Silica Gel $\mathrm{H}$ plate containing magnesium acetate $(2.5 \%)$, using chloroform/methanol/13.5 N ammonia water $(65: 35: 6, \mathrm{v} / \mathrm{v})$ in the 1 st dimension, and chloroform/acetone/methanol/acetic acid/ water $(3: 4: 1: 1: 0.5, \mathrm{v} / \mathrm{v})$ in the 2 nd dimension $^{8)}$. The concentration of each phospholipid on TLC plate was determined by the method of Rouser, et $a l^{9)}$ The fatty acid methylesters from phospholipids were prepared by the method of Morison and 
Smith $^{10)}$. The areas of phospholipids were scraped off the plates and transmethylated with $10 \% \quad \mathrm{BF}_{3} /$ methanol for analysis by gas-liquid chromatography. The methylesters were analyzed with a Shimadzu GC-6 gas chromatograph. Each sample was injected onto a glass column $(200 \mathrm{~cm})$ packed with $10 \%$ diethylenglycol succinate supported on Chromosorb W (80-100 mesh, Gaschro Kogyo Co., Tokyo). The column temperature was $185^{\circ} \mathrm{C}$ and the flow rate of the $\mathrm{N}_{2}$ carrier gas was $50 \mathrm{ml} / \mathrm{min}$. The unsaturation index is defined as $\Sigma$ ( (number of double bond of each fatty acid $) \times(\%$ of each fatty acid) ) ${ }^{11}$.

Chemicals were of the highest purity available from commercial sources.

\section{Results and Discussion}

As shown in Table 1, the content of membrane phospholipids per tissue wet weight was slightly higher in the sublingual gland than other two glands. This tendency did not change between male and female. In order to analyze phospholipids more in detail, total phospholipids were separated to each one and the composition was compared in the three salivary glands. Phosphatidylcholine and phosphatidylethanolamine were generally major constituents of membrane phospholipids and sphingomyelin, phosphatidylinositol, phosphatidylserine and so on were present as minor ones. The specific phospholipid for salivary glands was not observed and the phospholipid constituents were similar to the another rat tissues ${ }^{12)}$. When the phospholipid compositions were compared between the three salivary glands, they were almost the same in male rat. However, in the female, minor phospholipids, especially phosphatidylinositol and phosphatidic acid, were significantly higher than in the male. This characteristic was observed commonly in the three salivary glands. Phosphatidylinositol has been paid attention because of its rapid turnover, so called "PI effect", in response to various stimuli and this effect is a feature common to not only salivary glands but also to other secreting cells $^{13,14)}$. Furthermore, phosphatidic acid is one of the metabolite of phosphatidylinositol turnover. Therefore, the obtained results suggest the possibility of different responses to the various stimuli between male and female rat salivary glands.

The biological membrane functions are closely correlated with the physical state of membrane phospholipids ${ }^{15)}$ and their fatty acyl chains play very important role in it. Therefore, the fatty acid composition of total phospholipids was analyzed in the three major salivary glands. As shown in Table 2, the compositions of fatty acids were very common to the other tissues of rat $^{12)}$. Major saturated fatty acids were palmitic

Table 1 Comparison of phospholipid composition in male and female rat salivary glands

\begin{tabular}{|c|c|c|c|c|c|c|}
\hline & \multicolumn{2}{|c|}{ Parotid gland } & \multicolumn{2}{|c|}{ Submandibular gland } & \multicolumn{2}{|c|}{ Sublingual gland } \\
\hline & male $(7)^{a}$ & female (3) & male (7) & female (3) & male (7) & female (3) \\
\hline \multicolumn{7}{|l|}{ Total phospholipids $(\mu \mathrm{mol} / \mathrm{g}$} \\
\hline \multicolumn{7}{|l|}{ Each phospholipid (\%) } \\
\hline phosphatidylcholine & $45.9 \pm 4.03$ & $42.2 \pm 2.95$ & $44.4 \pm 1.32$ & $37.9 \pm 1.46$ & $45.3 \pm 1.21$ & $38.6 \pm 1.09$ \\
\hline phosphatidylethanolamine & $27.3 \pm 1.78$ & $24.4 \pm 1.82$ & $25.9 \pm 1.61$ & $23.7 \pm 0.78$ & $24.7 \pm 0.94$ & $22.4 \pm 1.07$ \\
\hline sphingomyelin & $7.1 \pm 1.41$ & $7.8 \pm 0.27$ & $7.6 \pm 0.73$ & $7.4 \pm 0.45$ & $7.7 \pm 1.61$ & $6.6 \pm 0.25$ \\
\hline phosphatidylinositol & $3.4 \pm 0.72$ & $4.9 \pm 1.76$ & $3.4 \pm 0.48$ & $5.0 \pm 0.67$ & $4.9 \pm 1.36$ & $6.4 \pm 0.52$ \\
\hline phosphatidylserine & $3.6 \pm 0.88$ & $4.3 \pm 1.91$ & $3.9 \pm 1.03$ & $4.3 \pm 0.24$ & $4.5 \pm 1.78$ & $4.7 \pm 0.24$ \\
\hline cardiolipin & $4.0 \pm 0.86$ & $4.4 \pm 0.23$ & $5.4 \pm 1.31$ & $5.3 \pm 0.41$ & $4.1 \pm 0.47$ & $5.2 \pm 0.06$ \\
\hline phosphatidic acid & $1.7 \pm 0.27$ & $3.1 \pm 0.06$ & $2.2 \pm 0.85$ & $3.5 \pm 0.38$ & $2.0 \pm 0.83$ & $4.2 \pm 0.30$ \\
\hline
\end{tabular}

a: Values in parenthese represent the number of expriment.

${ }^{b}$ : The average of two separate experiments. 
Table 2 Comparison of fatty acid composition of total phospholipids in male and female rat salivary glands

\begin{tabular}{|c|c|c|c|c|c|c|}
\hline \multirow{2}{*}{ Fatty acid (\%) } & \multicolumn{2}{|c|}{ Rarotid gland } & \multicolumn{2}{|c|}{ Submandibular gland } & \multicolumn{2}{|c|}{ Sublingual gland } \\
\hline & male (6) ${ }^{a}$ & female (2) & male (5) & female (2) & male (4) & female (3) \\
\hline C14:0 & 3.9 & 1.0 & 2.9 & 5.3 & 4.1 & 7.7 \\
\hline $\mathrm{C} 16: 0$ & 27.3 & 24.0 & 23.6 & 24.0 & 23.0 & 23.1 \\
\hline C16:1 & 2.0 & 1.5 & 1.9 & 1.3 & 2.4 & 3.0 \\
\hline C18:0 & 12.6 & 15.6 & 13.1 & 14.9 & 14.3 & 14.6 \\
\hline C18:1 & 11.1 & 12.6 & 10.0 & 10.3 & 11.0 & 11.2 \\
\hline C18:2 & 12.7 & 16.3 & 13.8 & 18.6 & 10.0 & 9.7 \\
\hline $\mathrm{C} 20: 3$ & 2.5 & 2.0 & 4.5 & 2.6 & 4.0 & 2.5 \\
\hline C20:4 & 18.1 & 19.5 & 18.5 & 15.5 & 21.1 & 19.0 \\
\hline $\mathrm{C} 22: 6$ & 2.1 & 1.8 & 1.3 & 1.0 & 1.8 & 0.9 \\
\hline Others & 7.7 & 5.7 & 10.4 & 6.5 & 8.3 & 8.3 \\
\hline Unsaturation Index & 131.0 & 141.5 & 134.8 & 124.6 & 140.6 & 122.5 \\
\hline
\end{tabular}

a: Values in parentheses represent the number of experiment.

and stearic acids, and arachidonic, oleic and linoleic acids were unsaturated ones. When the compositions were compared between the three glands, the characteristic constitution was observed in the fatty acids of which chain length is eighteen. In parotid and submandibular glands, the compositions of stearic and linoleic acids of total phospholipids were almost same and oleic acid was lower than in the two fatty acids. On the other hand, sublingual gland showed the fatty acid compositions in the order of stearic acid $>$ oleic acid $>$ linoleic acid. These tendencies were also observed regardless of male or female salivary glands. However, the fatty acid composition of total phospholipids is reflected by each phospholipid of which fatty acid shows a very characteristic composition $^{12)}$ and the phospholipid composition is also varied depending on the membrane from various organelles ${ }^{12,16)}$. In order to point out the specific differences in phospholipid and its fatty acid compositions between the three salivary glands, more detailed analysis of phospholipid will be required and is in progress in our laboratory.

\section{Acknowledgement}

This study was supported in part by the grant from the Ministry of Education, Culture and Science, Japan (No. 57570685 and No. 59771377).

\section{References}

1) Dowd, F., Watson, E. and Suddick, R. P.: Salivary gland metabolism. In: Handbook of Experimental Aspects of Oral Biochemistry (Edited by Lazzari, E. P.), pp. 285-306, CRC Press, Inc., Boca Raton, 1983.

2) Michell, R. H.: Inositol phospholipids and cell surface receptor function. Biochim. Biophys. Acta 415: 81-147, 1975.

3) Holub, B. J. and Kuksis, A.: Metabolism of molecular species of diacylglycerophospholipids. In: Advances in Lipid Research (Edited by Paoletti, R. and Kritchevsky, D.), pp. 793-826, Academic Press, New York, 1978.

4) Irvine, R. F.: How is the level of free arachidonic acid controlled in mammalian cells? Biochem. J. 204: 3-16, 1982.

5) Bligh, E. G. and Dyer, W. J.: A rapid method of total lipid extraction and purification. Can. J. Biochem. Physiol. 37: $911-$ 917, 1959.

6) Bartlett, G. R.: Phosphorus assay in column chromatography. J. Biol. Chem. 234: 466$468,1959$.

7) Marinetti, G. V.: Chromatographic separation, identification, and analysis of phosphatides. J. Lipid Res. 3: 1-20, 1962.

8) Imai, A., Yano, K., Kameyama, Y. and Nozawa, Y.: Reversible thrombin-induced modification of positional distribution of fatty acids in platelet phospholipids. Biochem. Biophys. Res. Commun. 103: 1092-1099, 
1981.

9) Rouser, G., Siakotos, A. N. and Fleischer, S.: Quantitative analysis of phospholipids by thin-layer chromatography and phosphorus analysis of spots. Lipids 1: 85-86, 1966.

10) Morrison, W. R. and Smith, L. M.: Preparation of fatty acid methyl esters and dimethylacetals from lipids with boron fluoridemethanol. J. Lipid Res. 5: 600-608, 1964.

11) Soodsma, J. F., Mims, L. C. and Harlow, R. D.: The analysis of the molecular species of fetal rabbit lung phosphatidylcholine by consecutive chromatographic techniques. Biochim. Biophys. Acta 424: 159-167, 1976.

12) White, D. A.: The phospholipid composition of mammalian tissues. In: Form and Function of Phospholipids (Edited by Ansell, G.
B., Hawthorne, J. N. and Dawson, R. M. C.), pp. 441-482, Elsevier/North-Holland Biomedical Press, Amsterdam, 1973.

13) Michell, R. H.: Inositol phospholipids in membrane function. Trends Biochem. Sci. 4: 128-131, 1979.

14) Hawthorne, J. N.: Is phosphatidylinositol now out of the calcium gate? Nature 295: 281-282, 1982.

15) Sandermann, H.: Regulation of membrane enzymes by lipids. Biochim. Biophys. Acta 515: 209-237, 1978.

16) Nijjar, M. S. and Pritchard, E. T.: Characterizaiton of plasma membranes isolated from rat submandibular salivary glands. Archs. Oral Biol. 17: 1679-1690, 1972. 